\title{
En torno de las dimensiones reales del capitalismo*
}

$\mathbf{E}$ L tema del capitalismo como fenómeno social, político y económico se ha tratado de manera abundante, pero en tres dimensiones distintas, aunque no excluyentes.

El capitalismo, sistema que ha favorecido tanto a tan pocos a costa de haber sacrificado tanto a tantos ha ocupado inumerables páginas de inumerables libros considerado, comentado en una sola dimensión, la que se entiende como dimensión teórica, a veces pseudoteórica. Es el capitalismo en teoría económica separado, arrancado de su historia, es decir, de su contexto humano, social. Es la tendencia a construir teorías socio-económicas en las nubes y de justificar su validez revistiéndolas con ropaje matemático para darles respetabilidad científica que no siempre logran, cayendo en la pseudociencia.

Este tratamiento cae en la unidimensionalidad, en la supuesta ciencia de las alturas sólo alcanzable por unos cuantos privilegiados y no se escapa del orgullo de aquel racionalismo acrítico, platónico que se expresa así: Yo poseo toda la verdad y sólo la verdad, escúchenla y síganla; los demás sólo poseen las sombras de las opiniones.

El capitalismo en dos dimensiones es el mismo fenómeno económico-social, pero en su escenario natural, en su espacio, en su tiempo, con sus hombres y hechos reales sin supuestos que suponen lo que no debe suponerse, por ejemplo que los hombres todos van a reaccionar de manera idéntica ante estímulos idénticos, o suponer que hay una mano muy real, aunque invisible, que hace justicia y reparte lo que los egoístas no comparten, que se constituye en agente de justicia distributiva. (¡Cuántas muer-

* Comentario de Carlos de la Isla en la presentación del libro "Desarrollo e Ideología en la formación del capitalismo" de Manuel Cazadero. 
tes ha causado la espera de que esta mano ínvisible se haga visible!).

Esta consideración sin supuestos, que muestra el fenómeno económico-social en su propio contexto constituye el tratamiento del capitalismo en dos dimensiones la teórica y la histórica; es decir, la que hace teoría a partir de la realidad.

Finalmente el mismo fenómeno: el capitalismo, pero contemplado en sus tres dimensiones; esto es cuando se toma en serio el fenómeno humano y se le quiere entender en su totalidad sin parcialidades ni mutilaciones: Es cuando se considera el hecho social en su escenario natural y además se investigan sus causas. Tres dimensiones: la teórica, la histórica y la filosófica.

Este estudio en tres dimensiones me parece no sólo el mejor, sino el único completo, aunque también, por supuesto, el más difícil.

Encuentro la obra de Manuel Cazadero: "Desarrollo, Crisis e Ideología en la Formación del Capitalismo" entre las raras, por escasas, obras en las tres dimensiones: El capitalismo, su desarrollo y crisis como fenómeno socio-económico y político, pero no abstraído de la realidad, no con la pretendida intención de hacer teoría revestida de ropaje pitagórico, sino mostrado, apresado en su dimensión histórica, con toda su relación viva de drama, tragedia y comedia, angustia, desesperación y fiesta como discurre el capitalismo en la historia humana. Pero la obra de Cazadero no se limita a esta segunda dimensión, la histórica, sino que explora cuidadosamente su relación causal que aventura la comprensión de la totalidad incursionando en la dimensión filosófica, la más dificil por más atrevida y completa.

Aparece esta dimensión especialmente en la influencia que la ideología tiene sobre todo el proceso de formación del capitalismo. Problema apasionante que, para mi gusto, imprime la dimensión más meritoria a esta obra, aunque a algunos economistas les parezca sin importancia, porque las ideas, dicen, no pueden cuantificarse de acuerdo a los modelos pitagóricos de la armonía perfecta.

Discurre Cazadero sin prisas, con fluída naturalidad y estilo mostrando los hechos más variados, solemnes y sutiles, pero también auscultando y apresando las ideas que mueven los hechos; porque Cazadero es filósofo y sabe que todo mundo vive de ideas y que, como reza el refrán oriental del S. VII A.C., "nuestros actos siguen a nuestras ideas como las ruedas de la carreta siguen las pezuñas del buey". 
De allí la importantísima relación causal de la ideología del inmanentismo y del trascendentalismo en el desarrollo y crisis del capitalismo; aspecto particular de este libro sobre el que quiero hacer una breve reflexión.

El estudio de Cazadero tiene que afrontar el inevitable problema de todas las ciencias sociales que tienden a explicar fenómenos humanos: el problema de la objetividad del conocimiento cuando el objeto de estudio son los seres humanos en sus relaciones reales.

$\mathrm{Si}$ aun en las ciencias físicas y naturales la objetividad que da derecho al carácter de "validez universal" queda resquebrajada en su misma base al demostrar Heisenberg que la sola observación del sujeto modifica el campo molecular observado. El objeto observado está penetrado de subjetividad y por tanto no es legítimo hablar de objetividad pura.

Con mayor razón tratándose del objeto de estudio de las ciencias sociales, cambiante por naturaleza si se les atribuye a los hombres un mínimo de libertad ¿cómo se podrá mencionar el conocimiento objetivo, universal y de leyes permanentes?

Algunos científicos sociales han abordado el problema por el camino de las matemáticas, con incontables variables, partiendo de supuestos supuestamente invariables. En este intento hacia la cientificidad pienso que lo que debe cuestionarse es la validez de los supuestos.

Otro camino, aun recorrido, en busca de la objetividad ha sido el determinista; escenario fácil hacia la objetividad científica, pero más sospechoso de falsedad. En este proceso el supuesto es: a estímulos iguales respuestas iguales.

Lo que equivale a reducir las conductas humanas a respuestas mecánicas. En este escenario se encuentran todos los determinismos: el psicológico, el sociológico, el histórico, el cosmológico, el teológico... desde los más burdos hasta los más disfrazados; of recen distintas razones, pero con el resultado común de presentar en escena a un hombre máquina o marioneta.

Es en este ámbito en el que la concepción marxista ha provocado también polémica y Cazadero la hace explícita al citar al principio de su libro (pág. 12) el famoso y debatido texto del prólogo a la Contribución de la Crítica a la Economía Política: "En la producción social de su existencia los hombres entran en relaciones determinadas, necesarias, independientes de su voluntad; estas relaciones de producción corresponden a un grado 
determinado de las fuerzas productoras materiales. El conjunto de estas relaciones de producción constituyen la estructura económica de la sociedad, la base real sobre la que se eleva una superestructura jurídica y política, y a la que corresponden determinadas formas de conciencia social. El modo de producción de la vida material condiciona el proceso de la vida social, política e intelectual en general".

Estas "relaciones determinadas, necesarias, independientes de su voluntad"' están sugiriendo ideas y comportamientos determinados. Si bien el señalamiento de Marx se orienta a mostrar las relaciones impuestas en el mundo de la necesidad en la sociedad capitalista, no deja por eso de expresar determinación, necesidad, negación de la libertad en dichas relaciones. Especialmente las últimas líneas de la cita nos introducen a la naturaleza cualitativa de tal relación. "El modo de producción de la vida material condiciona (en otras traducciones se usa el verbo determina) el proceso de la vida social, política e intelectual en general".

En el mismo texto Marx afirma: "no es la conciencia del hombre la que determina su ser, sino, por el contrario, el ser social es lo que determina su conciencia". Resulta clara la relación, que aparece determinante, entre el ser social, modo material de existencia y la formación de la conciencia; relación causal que se muestra más evidente en la formación de la ideología de la clase dominante. Determinación que va de la realidad material a la conciencia, de la economía a la filosofia, política, religión... siempre en ese orden, en esa dirección y sentido.

En este escabroso campo aparece el aspecto más sutil y apreciable de la obra de Cazadero. Afronta de entrada el problema; empieza por enunciar la ley de correspondencia: "Los distintos niveles de la actividad social de los hombres forman una totalidad en la que las transformaciones operadas en un nivel, sea el económico, el político, el ideológico, etcétera, repercuten en los otros, generando cambios correspondientes que tienden a mantener la coherencia del conjunto". (pág. 11).

En la enunciación de la ley el autor procede con suma cautela al elegir los términos: no expresa relación específica ni menos causal entre lo que designa como niveles. Se reduce a referir que todos los fenómenos sociales están interrelacionados, lo que no es difícil de aceptar. Y es que, por una parte quiere enfatizar la relación ineludible: "esta ley tiene un carácter objetivo. Su cumplimiento es independiente tanto de la voluntad humana como 
de la conciencia que los hombres tengan de ella"; pero, por otra parte, evitar el determinismo por razones evidentes: "Pero esta objetividad no debe interpretarse en su funcionamiento como una rigidez mecánica. Por el contrario, los nexos que vinculan los diversos elementos de la totalidad social son flexibles y permiten una autonomía relativa de diversas instancias, tales como el Estado y la ideología en relación con los procesos económicos". (pág. 13) Unos niveles de la actividad social repercuten (no se usa el término determinan) en los demás, pero no se expresan las relaciones causales específicas como en la idea de Marx en la que la estructura económica genera la superstructura jurídica, política, etc.

Por el contrario aquí se afirma la autonomía relativa de instancias como el Estado y la ideología en relación con los procesos económicos. Esto coincide con la afirmación de Engels: "Las últimas causas de la historia hay que buscarlas en la economía, no en la filosofía". Sin embargo, Marx afirma en $\mathrm{La}$ Ideología Alemana, cuando se refiere a la nueva concepción de la historia, la inegable interacción de la realidad material sobre los hombres y de estos sobre sus circunstancias: "Las circunstancias hacen a los hombres y viceversa", sería absurdo pensar que Marx definiera la causalidad en una sola dirección: de la economía a la ideología.

Es evidente la acción recíproca entre los hombres concretos y su medio concreto, lo que Cazadero expresa con toda claridad con el término y concepto "ecosis" que toma de León Portilla "como categoría para designar las consecuencias y cambios provocados por una sociedad sobre el medio natural; se puede decir que las sociedades establecen un diálogo con la naturaleza basado en sus mitos y creencias, pero dicho diálogo se lleva al cabo principalmente a través de su acción directa sobre su medio natural. Esta relación es recíproca, pues, si bien el medio condiciona y en cierta manera determina, es igualmente cierto que el hombre dotado de elementos culturales, incluso si estos son primitivos, actúa con planes y objetivos sobre el medio natural que ha escogido para vivir" (pág. 14).

Pienso que es válida y meritoria la metodología que esıablece y pone en práctica Cazadero señalando los interlocutores de diálogo entre los hombres agentes y pacientes, su medio y circunstancias, sus creaciones y quehaceres. Interrelación obligada, objetiva y en distintos niveles.

Se centra su estudio en la influencia de la ideología sobre la 
formación del capitalismo, su desarrollo, su crisis; y discurre por los siglos de su historia mostrando cómo la concepción que el hombre tiene de sí mismo como soberano, medida y motor de su historia (inmanentismo) o como súbdito, sujeto dependiente y condicionado a la trascendencia, porque existe el Trascendente (trascendentalismo) influye y hasta determina el comportamiento social que se manifiesta en el desarrollo y crisis del capitalismo.

Pero el autor no excluye otros niveles, otros factores de la dialéctica acción-pasión, por el contrario invita a seguir otras rutas: "Otra ruta de investigación la ofrece el nexo entre el progreso de la ciencia y la tecnología por un lado y el desarrollo del capitalismo por el otro" (pág. 140). Apasionante tarea de abrir y recorrer rutas que conduzcan al conocimiento de los hombres en el tiempo. 